\title{
Interprofessional approaches to integrating SBIRT into students' clinical experiences
}

\author{
Heather Gotham", Sarah Knopf-Amelung ${ }^{1}$, Ile Haggins², Jolene Lynn¹, Pam Young ${ }^{1}$, Ronalda Manney', \\ Kendall Kohnle ${ }^{1}$ \\ From INEBRIA 12th Congress, \\ Atlanda, GA, USA. 24-25 September 2015
}

\section{Background}

Most healthcare professional training programs lack sufficient curricula on substance use[1-3], and even fewer provide students the opportunity to practice screening and brief intervention (BI) in a clinical setting. The University of Missouri-Kansas City Screening, Brief Intervention and Referral to Treatment (UMKC-SBIRT) training project educates baccalaureate nursing (BSN), doctorate of nursing practice (DNP), and master of social work (MSW) students through didactics, role plays with classmates, standardized patient practice, and clinical experience to help students achieve competency.

\section{Material and methods}

In year two of the project, students training began integrating SBIRT into their clinical experiences. Implementation packets were distributed to students with resources and instructions tailored to fit the varied needs of the programs and clinical sites. Clinical practice was supervised by SBIRT-trained clinical preceptors when possible or self-evaluated by students using the Brief Intervention Observation Sheet fidelity scale. Qualitative feedback was collected from faculty, clinical preceptors, and students to identify facilitators and barriers to integration of SBIRT into clinical experience.

\section{Results}

Preliminary data showed that 56 students (33 BSN, 23 MSW) practiced SBIRT at their clinical site during the first semester of implementation, with $9 \%$ completing screening only (no BI indicated) and $91 \%$ completing screening and BI. Fidelity ratings revealed strong

\footnotetext{
* Correspondence: gothamhj@umkc.edu

${ }^{1}$ School of Nursing \& Health Studies, University of Missouri-Kansas City, Kansas City, USA

Full list of author information is available at the end of the article
}

completion of BI steps with no significant difference between the groups (BSN fidelity mean $=9.44 / 10$, MSW fidelity mean $=9.30 / 10$ ), although BSN students demonstrated stronger motivational style $(\mathrm{t}=2.47, \mathrm{p}=.017)$. Qualitative data revealed institutional barriers to integrating SBIRT into some nursing clinical sites, while MSW clinical sites generally facilitated student practice and some adopted SBIRT agency-wide.

\section{Conclusions}

Students need opportunities to integrate SBIRT practice into clinical experience and receive supervised feedback to achieve competency. Plans must be tailored to meet the institutional needs of clinical sites, which can vary for BSN and MSW students.

\section{Acknowledgements \\ This work was supported by grant T1025355 from the Department of Health and Human Services, Substance Abuse and Mental Health Services \\ Administration. \\ Authors' details \\ ${ }^{1}$ School of Nursing \& Health Studies, University of Missouri-Kansas City, Kansas City, USA. ${ }^{2}$ School of Social Work, University of Missouri-Kansas City, Kansas City, USA.}

Published: 24 September 2015

\section{References}

1. Russett J, Williams A: An exploration of substance abuse course offerings for students in counseling and social work programs. Subst Abus 2015, 36:51-58.

2. Mollica M, Hyman Z, Mann C: Alcohol related content in undergraduate nursing curricula in the northeastern United States. J Psychosoc Nurs Ment Health Serv 2011, 49:22-31.

3. Finnell D: A clarion call for nurse-led SBIRT across the continuum of care. Alcohol Clin Exp Res 2012, 36:1134-1138.

\section{doi:10.1186/1940-0640-10-S2-O21}

Cite this article as: Gotham et al:: Interprofessional approaches to integrating SBIRT into students' clinical experiences. Addiction Science \& Clinical Practice 2015 10(Suppl 2):O21.

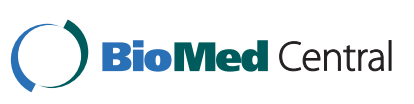

(c) 2015 Gotham et al. This is an Open Access article distributed under the terms of the Creative Commons Attribution License (http:// creativecommons.org/licenses/by/4.0), which permits unrestricted use, distribution, and reproduction in any medium, provided the original work is properly cited. The Creative Commons Public Domain Dedication waiver (http://creativecommons.org/publicdomain/ zero/1.0/) applies to the data made available in this article, unless otherwise stated. 